Пинчук Антонина Николаевна

соискатель кафедры социологии и культурологии Кубанского государственного аграрного университета им. И.Т. Трубилина

\section{ОБРАЗОВАТЕЛЬНЫЕ ПРАКТИКИ В УСЛОВИЯХ ОБНОВЛЕНИЯ ОБРАЗОВАТЕЛЬНЫХ ТЕХНОЛОГИЙ ВУЗА}

\section{Аннотация}

Внедрение инновационных образовательных технологий в образовательный процесс высшей школы способно качественно изменить привычные способы и методы преподавания, закладывая тем самым фундамент нового способа подготовки современного специалиста, обладающего необходимым набором компетенций. В статье обращено внимание на то, какие новые образовательные практики формируются в связи с распространением инновационных образовательных технологий.

Ключевые слова:

государственная политика, модернизация высшей школы, информатизация образовательного пространства, инновационные образовательные технологии, образовательные практики.
Pinchuk Antonina Nikolayevna

PhD student, Social Science and Cultural Studies Department, Kuban State Agrarian University

\section{EDUCATIONAL PRACTICES IN THE CONTEXT OF RENOVATION OF UNIVERSITY EDUCATIONAL TECHNOLOGIES}

Summary:

Introduction of innovative educational technologies in the educational process of a higher school is able to change qualitatively the usual ways and methods of teaching, thus laying the foundation of a new way of training of modern specialists with necessary competences. The article considers which educational practices form the innovative educational technologies.

Keywords: public policy, modernization of higher education, informatization of educational space, innovative educational technology, educational practices.

Современная российская сфера образования переживает сложнейший период реформирования, подвергается обновлениям институционального и содержательного характера, ведущим к созданию системы, адаптированной к потребностям сектора национальной экономики и успешно интегрированной в социально-экономическую инфраструктуру страны. Мощнейшие трансформационные процессы, связанные с переходом к трехуровневой модели образования и переориентацией на компетентностную парадигму, требуют в свою очередь планомерного определения в рамках организационно-правового регулирования новых позиций и отношений субъектов образовательной деятельности.

Траектории развития и модернизации системы образования, изложенные в Концепции долгосрочного социально-экономического развития Российской Федерации на период до 2020 года [1] и в государственной программе Российской Федерации «Развитие образования» на 20132020 годы [2], продолжают поэтапно реализовываться и сегодня. Так, для достижения приоритетных целей государственной политики Правительством Российской Федерации была принята актуальная для последующего периода Федеральная целевая программа развития образования на 2016-2020 годы [3]. В данной программе в совокупности важных задач обозначен курс на «...модернизацию образовательных программ, технологий и содержания образовательного процесса на всех уровнях профессионального образования через внедрение новых вариативных образовательных программ на основе индивидуализации образовательных траекторий с учетом личностных свойств, интересов и потребностей обучающегося...» [4, с. 5]. Масштаб и значимость необходимых нововведений в сфере высшего образования очевидны и преимущественно осуществляются в комплексе мер, среди которых инноватизация образовательных программ и технологий относится к доминирующим.

Следует заметить, что в поле научного дискурса проблематика разработки и внедрения инновационных педагогических технологий вуза достаточно актуализирована и продолжает активно обсуждаться представителями различных областей социально-гуманитарного знания. Так, в научной периодике всесторонне освещаются педагогические технологии, включающие современные электронные устройства и средства связи [5]. Не остаются за рамками внимания и дистанционные [6], интерактивные [7] образовательные технологии, рассматриваемые, как правило, в контексте постановки вопроса о поиске путей их качественной реализации в практике оказания образовательных услуг. Отразить социальные проблемы и сложности, возникающие в 
контексте реформирования профессионального образования, способна и социологическая информация. Так, в рамках социологии повседневности можно сконцентрировать внимание на появлении новых атрибутов повседневной реальности и привычного уклада существования современных вузов, так как использование в процессе преподавания инновационных образовательных технологий предполагает изменение прежних методов и средств трансляции знаний и тактик учебно-педагогического взаимодействия. Это в свою очередь не может не вызывать интерес к тому, какие типизированные способы обучения формируются у самих студентов, то есть какие образовательные практики, которые являются разновидностью социальных практик в образовательной среде, конструируют новые образовательные технологии высшей школы.

Если непосредственно обратиться к основным видам педагогических технологий последних моделей, то прежде всего отметим их информатизацию, происходящую в русле создания развитого российского информационного пространства. Многими авторами подчеркивается широкий диапазон возможностей, которые появляются в ходе компьютеризации образовательного процесса, позволяющей значительно интенсифицировать и оптимизировать обмен информацией между субъектами учебной деятельности [8]. Причем реконструируются и организационнотехнические аспекты учебной деятельности. Так, оснащенность необходимым оборудованием учебных аудиторий, бесперебойный доступ к сети Интернет и компьютерная грамотность преподавателей и студентов становятся базовыми условиями осуществления педагогического процесса. На смену классическим бумажным носителям постепенно приходят цифровые форматы данных, а электронные учебники, справочники, специальные программы, виртуальные учебные комплексы, обучающие аудио- и видеолекции начинают составлять основной объем образовательных материалов и источников [9]. В таких условиях формируются новые опривыченные способы овладения и получения дисциплинарных знаний. Студенты учатся работать с цифровыми источниками данных, привыкают получать информацию из сетевых ресурсов. Более того, стало возможным усваивать материал самостоятельно через аудио- и видеодемонстрацию.

Тем самым виртуализация образовательной среды формирует характерные для ее новых свойств образовательные практики. Но, несмотря на явные преимущества работы с электронными форматами данных (скорость, точность, визуализация, возможность повтора и т. д.), существуют и определенные сложности. Как отмечает С.Б. Лазутин, «с первых дней использования электронных инфрормационных ресурсов (ЭИР) начались трудности. И одна из основных заключалась в том, что пользовательский интерфейс в каждом ЭИР имел значительные отличия от других. То есть приходится сначала учиться работать с данным электронным изданием и только потом изучать предмет» [10, с. 1041]. Получается, что появляется новая образовательная практика: сначала следует освоить процедуры работы с самой образовательной программой, запомнить основные операции, а затем приступить к изучению учебного материала. Причем сам автор в качестве оптимального решения предлагает унифицировать и стандартизировать интерфейс пользователя в целях возможности многократного использования учебных объектов «в другом месте с другими инструментами и платформами» [11, с. 1042].

Переход к информационным технологиям и возможность виртуального общения с удаленным доступом к различным серверам привели к зарождению новой формы обучения - дистанционной. Данная форма обучения позволяет реализовывать учебный план посредством самостоятельного изучения материалов, расположенных на специализированных интернет-ресурсах, в совокупности с виртуальным общением с преподавателем с помощью электронной почты, видеоконференций, диалогов в онлайн-режиме и т. д. [12].

Дискуссии о достоинствах и недостатках дистанционных технологий продолжаются до сих пор [13]. Достаточно констатировать, что их дальнейшее развитие и внедрение остаются актуальными. В связи с этим возникает вопрос о тех образовательных практиках, которые конструируются при дистанционном обучении. Студенты в данном случае не посещают лекционно-семинарские занятия, не взаимодействуют с сокурсниками. Многие виды интерактивных педагогических технологий, предполагающие коллективное участие и обсуждение, в принципе исключаются. Здесь больше делается упор на самостоятельную работу. Хотя то, каким образом студент ее организует, как складывается его индивидуальный процесс обучения, актуализируемый посредством дистанционных технологий, не менее интересно.

Например, Ч.Б. Миннегалиева провела исследование с целью изучения деятельности студентов в системе дистанционного обучения, выявления «особенностей использования дистанционных технологий, которые могут привести к снижению качества обучения» [14, с. 40]. В ходе эксперимента автор замечает, что учащимся «трудно заставить себя заниматься, для этого требуется самодисциплина; находясь за компьютером в интернете, легко переключиться на наиболее интересные сервисы, например социальные сети» [15, с. 41]. 
Проверка уровня знаний также остается проблемой. Так, при прохождении тестов возможно применение таких способов, как поиск ответа в электронных справочниках или поисковых системах. В качестве ухода от такой практики автор предлагает «составление открытого банка, включающего достаточное количество (100-200) вопросов, из которых во время аттестации студент ответит на случайным образом отобранные 40-60» [16, с. 42].

Предполагается, что более детальное исследование образовательных практик в данном случае способно стать весьма убедительным подспорьем в корректировке самостоятельной деятельности студентов.

Всплеск общего внимания, вызванный информатизацией образовательной среды, усиливает интерес и к изменяющейся традиционной роли преподавателя в новых реалиях. Сегодня признается важным интерактивное обучение, которое построено на значимости сотрудничества и взаимодействия студентов и педагогов, студентов различных курсов, самих преподавателей в образовательном процессе В данном случае важно выстраивание как вертикальных, так и горизонтальных связей между участниками учебно-педагогического взаимодействия. Благодаря данному подходу выполняется одна из задач формирования общекультурной компетенции, а именно формируются способность будущего специалиста успешно функционировать в коллективных формах деятельности и его готовность к плодотворному сотрудничеству [17].

Интерактивные методы обучения разнообразны по своему содержанию. Они включают проведение лекций-дискуссий, лекций-диалогов, лекций-бесед. Существенным дополнением являются семинарские занятия (семинары-беседы, семинары-дискуссии, семинары-конференции, семинары-игры, рефлексивные семинары и т. д.) [18]. То есть передача учебной информации в традиционной, скорее директивной, форме заменяется более гибким, ориентированным на творческий потенциал студента общением.

Типизация такого способа взаимодействия закрепляет соответствующие образовательные практики. В данном контексте показательны данные анкетирования, проведенного башкирскими исследователями с целью анализа текущей ситуации в российских вузах, сложившейся в ходе внедрения инновационных методов обучения. Так, ученые фиксируют, что «преподаватели гораздо более осторожно и взвешенно (и в какой-то мере консервативно) относятся к соотношению апробированных и новейших фрорм и методов работы, продолжают достаточно высоко оценивать полезность традиционных форм учебной работы: лекций, семинаров, лабораторных работ и т. п.» $[19$, с. 1874]. Возможно, в данном контексте следует решить вопрос оптимального соотношения инновационных и традиционных методик преподавания, с учетом того, какие образовательные практики они фрормируют.

Согласимся, успешность достижения целей и задач учебного плана во многом «зависит не только от того, что усваивается (содержание обучения), но и от того, как усваивается» [20, с. 25]. Речь идет об индивидуальной или коллективной работе, о том, в каких условиях - авторитарных или гуманистических - осуществляется процесс обучения, «с опорой на внимание, восприятие, память или на весь личностный потенциал человека, с помощью репродуктивных или активных методов обучения» [21]. Не менее важным оказывается и ответ на вопрос, какие образовательные практики закрепляет та или иная методика и тактика обучения.

Широкое использование инновационных технологий в педагогической деятельности способно отразить в облике современного вуза черты модернизированной, высокотехнологичной организации, отвечающей требованиям времени, в полной мере соответствующей критериям заявленного уровня качества оказываемых услуг. Причем облик высшей школы - многогранный, многоаспектный, охватить его в комплексе сложно, но видеть его многосторонность важно, ведь образовательный процесс представлен не только образовательными программами, стандартами, педагогическими технологиями, но и образовательными практиками, которые также являют собой одну из граней образовательной реальности.

\section{Ссылки:}

1. Концепция долгосрочного социально-экономического развития Российской Федерации на период до 2020 года [Электронный ресуpc]. URL: http://www.ifap.ru/ofdocs/rus/rus006.pdf (дата обращения: 21.09.2016).

2. Государственная программа Российской Федерации «Развитие образования» на 2013-2020 годы ГЭлектронный реcypc]. URL: http://bolplotds.ucoz.net/FEDERAL/gos_programma_razvitija_obrazovanija.pdf (дата обращения: 21.09.2016).

3. Федеральная целевая программа развития образования на 2016-2020 годы [Электронный ресурc]. URL: http://government.ru/media/files/mlorxfXbbCk.pdf (дата обращения: 21.09.2016).

4. Там же. С. 5 .

5. Кеменов П.А. Применение информационных технологий в процессе обучения в вузе // Человек и образование. 2009. № 3. С. $146-148$.

6. Попова Н.Е., Чикова О.А. Технологии дистанционного обучения как инновация в процессе реализации образовательных стандартов нового поколения // Вестник Новосибирского государственного педагогического университета. 2014. № 2 (18). C. 17-26. 
7. Макаренко О.В. Интерактивные образовательные технологии в вузе // Высшее образование в России. 2012. № 10. C. $134-139$

8. Кеменов П.А. Указ. соч.

9. Арзуманова Н.В. Использование современных информационных технологий в образовательном процессе // Известия Российского государственного педагогического университета им. А.И. Герцена. 2009. № 113 (18). С. 86-90.

10. Лазутин С.Б. Эффективность использования новых образовательных технологий // Вестник Тамбовского университета. Серия: Естественные и технические науки. 2009. Вып. 5, т. 14. С. 1041-1046.

11. Там же. С. 1042.

12. Рак Е.А. Особенности применения дистанционных технологий обучения в виртуальном образовательном пространстве вуза // Власть. 2010. № 10. С. 74-76.

13. Попова Н.Е., Чикова О.А. Указ. соч.

14. Миннегалиева Ч.Б. Некоторые проблемы применения дистанционных образовательных технологий // Интеграция образования. 2013. № 1 (70). С. 39-43.

15. Там же. С. 41.

16. Там же. С. 42.

17. Макаренко О.В. Указ. соч.

18. Соколова О.А. Образовательные технологии интерактивного обучения в высшем профессиональном образовании // Наука. Искусство. Культура. 2014. № 3. С. 195-199.

19. Бурханова Ф.Б., Родионова С.Е. Внедрение инновационных активных и интерактивных методов обучения и образовательных технологий в российских вузах: современное состояние и проблемы // Вестник Башкирского университета. 2012. № 4 (17). С. 1862-1875.

20. Кирикова М.И. Современные методы обучения в вузе // Сборники конференций НИЦ Социосфера. 2012. № 23. С. 25-31.

21. Там же. С. 25.

\section{References:}

Arzumanova, NV 2009, 'The use of modern information technologies in the educational process', Izvestiya Rossiyskogo gosudarstvennogo pedagogicheskogo universiteta im. A.I. Gertsena, no. 113 (18), pp. 86-90, (in Russian).

Burkhanova, FB \& Rodionova, SE 2012, 'Introduction of innovative active and interactive training methods and educational technologies in Russian universities: the current state and problems', Vestnik Bashkirskogo universiteta, no. 4 (17), pp. 18621875, (in Russian).

Kemenov, PA 2009, 'Application of information technologies in the process of education in the higher educational institution', Chelovek i obrazovaniye, no. 3, pp. 146-148, (in Russian).

Kirikova, MI 2012, 'Modern training methods in the higher educational institution, Sborniki konferentsiy NITS Sotsiosfera, no. 23, pp. 25-31, (in Russian).

Lazutin, SB 2009, 'Efficiency of using new educational technologies', Vestnik Tambovskogo universiteta. Seriya: Yestestvennyye i tekhnicheskiye nauki, Issue 5, vol. 14, pp. 1041-1046, (in Russian).

Makarenko, OV 2012, 'Interactive educational technologies in the higher educational institution', Vyssheye obrazovaniye $v$ Rossii, no. 10, pp. 134-139, (in Russian).

Minnegalieva, ChB 2013, 'Some problems of using distance educational technologies', Integratsiya obrazovaniya, no. 1 (70), pp. 39-43, (in Russian).

Popova, NE \& Chikova, OA 2014, 'Technologies of distance learning as an innovation in the course of implementation of educational standards of new generation', Vestnik Novosibirskogo gosudarstvennogo pedagogicheskogo universiteta, no. 2 (18), pp. 17-26, http://dx.doi.org/10.15293/2226-3365.1402.02.

Rak, EA 2010, 'Features of the application of distance learning technologies in the virtual educational space of the higher educational institution', Vlast', no. 10, pp. 74-76, (in Russian).

Sokolova, OA 2014, 'Educational technologies of interactive learning in higher professional education', Nauka. Iskusstvo. Kul'tura, no. 3, pp. 195-199, (in Russian). 